\title{
Coloured Algebras AND BiologicAl RESPONSE IN QUANTUM BIOLOGICAL COMPUTING ARCHITECTURES
}

\author{
${ }^{1}$ L-F Pau and ${ }^{2}$ P. Borza \\ ${ }^{1}$ CBS, Solbjergplads 1, DK 2000 Copenhagen, Denmark. Email: 1pau@nypost.dk \\ (Corresponding author) \\ ${ }^{2}$ Faculty of Electrical Engineering and Computers, Department Electronics \& Computers, \\ Street Politehnicii no.1-3, Brasov, 500024, Romania
}

\begin{abstract}
This paper reports about progress in two areas towards quantum computing architectures with elements inspired from biological controls, as proposed in an earlier paper. The first area is about exploiting mathematical results in coloured algebras, which, combined with the colouring of particle flows, would reduce the decoherence and enhance the decidability in the quantum processing elements; definitions are being recalled, with the required assumptions and results. The second area is to provide experimental results, and a patented biological feedback process in synapse, about light and acoustic excitations in a live animal species to enhance reactivity; the experimental set-up is characterized, the measurement results provided, and the implications are explicated for quantum processing elements approximating a synapse. A paragraph on open issues explains how the results in the two areas will be combined and will help in the design a very early compiler version.
\end{abstract}

\section{KEYWORDS}

Quantum computing architecture; quantum biological computing; coloured algebras; decoherence; synapse control; light and sound excitation of live creatures

AMS Classifications: 46N50, 81P68, 68Q05, 81Q35,81R50,92XX,17B75

\section{INTRODUCTION}

Quantum computing and its underlying theoretical approaches have made significant progress recently (Mermin N.D.,2007) (M.A. Nielsen M.A. \& Chuang I.L. ,2010) (Schäfer V.M. et al,2018) (Watson T.F. et al ,2018). A two-qubit SiGe processor has been reported (Watson T.F. et al ,2018), where the qubits have a lifetime of several milliseconds, against 10-100 micros for super conductive elements. Soon trapped ions will have a reminiscence of 1 min (Schäfer V.M. et al, 2018).

However, in terms of architectures less progress has been achieved for quantum computers because of the requirements for migration / interoperability with Instruction set architecture (ISA) as used in instruction or data flow traditional architectures; they generally still rely on exploiting at best the link between binary logic and qubits. Traditional computer architectures with binary

DOI: $10.5121 /$ ijcsit.2019.11401 
logic rely on functional blocks such as: gates, registers, common (Von Neumann) or shared (Harvard) memory, data flows, instruction flows, spatial distribution, time-based distribution, functional pathways.

In an earlier paper Borza P.N. \& Pau L.-F. (2016) explored a path towards quantum computing architectures exploiting jointly specific identified biological processes and some effects in particle physics underpinning a quantum functional realization of these biological processes. That paper also included an extended literature survey which is not reproduced here. The main advantage of this new architecture is the much more compact realization in quantum processing technology of the corresponding functions instead on relying on recursive calculations. The derived architectural building blocks were proposed, and a comparison made for programmability. Such biology-inspired functional pathways can be implemented inside structured matter, e.g. with delay generators, bifurcations, etc. For example, in the case of heart conduction, the pump functionality is obtained by spatial pathways and implicit delays in control signals propagation ; the nodes involved are : sino-atrial node, atrio-ventricular node, Hiss bundle, and Purkinje fibre terminations, and together they realize the aspire-repellent pump, which in turn mimics a class of functional computations in fluid dynamics. As another example, it is reminded that strings of proteins travel around a circuit in parallel controlled ways, as used in model bio-computers (ABACUS European Union FP7-ICT Project,2016).

The quantum equivalent building blocks rely on a realization by quantum charge collector islands, propagation "pathways" where conduction is performed in a ballistic mode, deflection elements (lattice, Berry cones, FET's, and Moiré based sub-lattice implementing spatial interferential computing).

The purpose of the present paper is to further validate two aspects of this biological inspired quantum processing architecture (Borza P.N. \& Pau L.-F.,2016):

1) Coloured algebras (Beckmann A., Mitrana V. \& Soskova M.,2015), formalize labelled initial symbols, groups, rings, and their various properties (especially commutativity or non-commutativity, and transitivity or non-transitivity) and operands; thus they allow to model the interactions inside functional blocks and at the same time classifying them by attribute ranges linked to energy levels. Thus, the coloured algebra maps the functional outcomes carried by qubits, when the quantum energies interact along the pathways; it is also in this paper shown that this linking has profound implications on ensuring decidability in the bio-inspired architecture, which was earlier an open issue;

2) Laboratory measurements on mice and rats about biological pathway processing; they deal with the nervous load due to intensity of excitation signals and allow to characterize the interactions along nervous pathways in neural synapses' metabolism when they mimic quantum energy interactions. The ability to link the energy and information flow with the neural metabolism is covered by a patent by one of the authors (Restian A., Borza P. N., Daghie Mircea V., \& Nicolau N. ,1985). The live reaction processes revealed by these experiments allow to shape the quantum block's excitations when synapses are involved in the functional blocks.

The implications for the modelling of the new architecture are thereafter summarized, and they are included in on-going realization focussed research. 
It should be noted in introduction to focus area 1) that the specification of the colours used is general, while they would be a specific discrete set in any technology realization. It should also be noted in introduction to focus area 2), that this paper does not rely as in (Lucks J.B. \&Arkin A.P. ,2011) on cell manipulation nor synthetic biology, but on experimental measurements.

\section{Coloured Algebras}

\subsection{Scope}

The idea is that one same coloured algebra can map uniquely the functional outcomes carried by qubits, when their quantum energies interact along the pathways in one given functional block from the proposed architecture. As such, one coloured algebra constitutes the functional image of a functional block, which can be used in programming.

\subsection{Basic Notations}

$-\mathrm{S}$ is a countable set;

$-\mathrm{A}$, a numbering of $\mathrm{S}$; it is a map $\mathrm{v}$ from the set $\mathrm{N}$ of natural numbers on the set $\mathrm{S}$;

-A numbering $\mathrm{v}$ is a Friedberg numbering if $\mathrm{v}$ is one on one;

-CONS is the symbol representing a constructive function, which allocates and fills records in recursive, side-effect free procedural languages (Vuillemin J. ,1974).

-g denotes a standard numbering of all finite subsets of $\mathrm{N}$; in particular if $\mathrm{n}(0)<\ldots \ldots<\mathrm{n}(\mathrm{k})$, then: $\mathrm{g}(2 \mathrm{n}(0)+2 \mathrm{n}(1)+2 \mathrm{n}(\mathrm{k}))=\{\mathrm{n}(0), \ldots \ldots, \mathrm{n}(\mathrm{k})\}$

$-|\mathrm{A}|$ is the cardinality of $\mathrm{A} \in \mathrm{N}$;

$-\{$ phii $\}, \mathrm{i} \in \mathrm{N}$, is a standard effective enumeration of all unary partial computable functions;

-for a function $\mathrm{f}$, df denotes the domain of $\mathrm{f}$, and $\mathrm{rf}$ denotes the range of $\mathrm{f}$;

- While a quantum «bit» is described by 2 coefficients:

$|\mathrm{Phi}>=\mathrm{c}(0)| 0>+\mathrm{c}(1) \mid 1>, \mathrm{n}$ «qubits» can be described not by $2 \mathrm{n}$ but by $2 \mathrm{n}$ coefficients:

$|\mathrm{Phi}>=\mathrm{c}(0,0, . ., 0)| 00 . .0>+\mathrm{c}(0,0, . ., 1 \mid 00 . .1>+\ldots+\mathrm{c}(1,1, . ., 1 \mid 11 . .1>$;

- Composite quantum system and Tensor product: a composite quantum system of linear spaces $\mathrm{HA}$ and $\mathrm{HB}$ is given by the tensor product space HA $\otimes \mathrm{HB}$. When HA and HB have their CONS's $\{\mid v i\} \mathrm{kl} \mathrm{i}=1, \ldots, \mathrm{k}\}$ and $\{\mid \mathrm{uj}\} \mathrm{l} \mathrm{j}=1, \ldots, 1\}$, respectively, the tensor product space $\mathrm{HA} \otimes \mathrm{HB}$ is given as the linear space whose CONS is $\{|v i, u j| 1 \leq i \leq k, 1 \leq j \leq 1\}$. One might consider that the composite system is given as the product space $\mathrm{HA} \oplus \mathrm{HB}$. The composite system is obtained as the tensor product space $\mathrm{HA} \otimes \mathrm{HB}$. Remember that the product space $\mathrm{HA} \oplus \mathrm{HB}$ has the CONS $\{\mid \mathrm{vi}\} \mathrm{kli}=1\} \mathrm{U}$ $\{$ luj $\} 1 \mathrm{j}=1\}$. 


\subsection{Basic Definitions}

Definition 1:an L-structure $M$ is an atomic model if, for any tuple $\hat{a}=(a(1), \ldots, a(n))$ from $M$, there exists an L-formula phi $(\mathrm{x}(0), \ldots, \mathrm{x}(\mathrm{n}))$, and every L-formula psi $(\mathrm{x}(0), \ldots, \mathrm{x}(\mathrm{n}))$, such that $\mathrm{M}=$ phi( $\hat{\mathrm{a}})$, and every L-formula $\mathrm{psi}(\mathrm{x}(0), \ldots, \mathrm{x}(\mathrm{n}))$, satisfy the following condition :

"If $\mathrm{M}=\operatorname{psi}(\hat{\mathrm{a}})$, then: $\forall \mathrm{x}(0), \ldots, \mathrm{x}(\mathrm{n}) \mathrm{M}:=((\operatorname{phi}(\mathrm{x}(0), \ldots \ldots, \mathrm{x}(\mathrm{n})) \square \operatorname{psi}(\mathrm{x}(0), \ldots, \mathrm{x}(\mathrm{n})))$ “

In such a formula phi(.) is called a complete formula of the theory M. There is a Vaught's theorem on the relationship of prime and atomic models (Chang C.C. \& Keisler H.J. ,1973), and a theorem by Jockusch and Soare on the relationship to decidable structures (infinite trees) (JockuschC.G. \& SoareR.I., 1972), (CenzerD. ,2000).

Definition 2: According to the classic formalization of generative grammars, first proposed by Noam Chomsky in the 1950s(Chevalley C., 1956), a grammar G consists of the following components:

- A distinguished symbol $\mathrm{S}$ in Nthat is the start symbol, also called the sentence symbol.

- A finite set $\mathrm{N}$ of nonterminal symbols, disjointfrom the strings formed from $\mathrm{G}$.

- A finite set Sigma of terminal symbols that is disjoint from N.

- A finite set $\mathrm{P}$ of production rules, where each rule has the form:

$(\operatorname{Sigma} U N) * N(\operatorname{Sigma} U N) *->(\operatorname{Sigma} U N) *$

where * is the Kleene star operator and $U$ denotes set union. In other words, each production rule maps one string of symbols to another, where the first string (the "head") contains an arbitrary number of symbols, on the condition that at least one of them is a nonterminal. However, when the second string (the "body") consists solely of the empty string, containing no symbols at all, it may be denoted with a special notation (often $\lambda$, e or $\varepsilon$ ) in order to avoid confusion. A grammar is then formally defined as the tuple (N, Sigma, P, S). Such a formal grammar is often called a rewriting system (or a phrase structure grammar in the literature), and it produces a language (Markl M. ,1992).

Definition 3: Definition of a group (Chevalley C.,1956). Let $\mathrm{G}$ be a non-empty set, and let $\star$ be a binary operation ("bop") on G:

(bop) $\star: ~ G \times G \rightarrow G(a, b)$

Then $(\mathrm{G} ; \star)$ is a group, if the following axioms are satisfied:

G1) associativity: $\forall \mathrm{a}, \mathrm{b}, \mathrm{c} \in \mathrm{G}: \mathrm{a} \star(\mathrm{b} \star \mathrm{c})=(\mathrm{a} \star \mathrm{b}) \star \mathrm{c}$

G2) identity element e: $\exists$ e $\in G: \forall a \in G: a \star e=e \star a=a$

G3) inverses: $\forall \mathrm{a} \in \mathrm{G}: \exists \mathrm{a}-1 \in \mathrm{G}: \mathrm{a} \star \mathrm{a}-1=\mathrm{a}-1 \star \mathrm{a}=\mathrm{e}$.

If, in addition, the following holds:

G4) commutativity: $\forall \mathrm{a}, \mathrm{b} \in \mathrm{G}: \mathrm{a} \star \mathrm{b}=\mathrm{b} \star \mathrm{a}$,

, then $(\mathrm{G} ; \star)$ is called an Abelian group, or simply a commutative group.

If the set $\mathrm{G}$ is finite, we define the order of $\mathrm{G}$ to be the number of elements in $\mathrm{G}$ and denote it $\mid \mathrm{Gl}$. Otherwise we say that this group $\mathrm{G}$ has infinite order.

Note that (bop) is an essential part of the definition; also (G2) must precede (G3) because (G3) refers to the element e. 
Note the fact that, if $(\mathrm{G} ; \star)$ is a group, then the identity e is unique and the inverse a-1of any a in $\mathrm{G}$ is uniquely determined by $\mathrm{a}$.

Definition 4: a) Let L(BA) be the language $\{\mathrm{V} 2$, Lambda2, $\mathrm{C} 1 ; 0,1\}$. We treat Boolean algebras as $\mathrm{L}(\mathrm{BA})$ structures. If $\mathrm{LC}$ is a linear ordering, then Int (LC) denotes the corresponding interval algebra. For a Boolean algebra B, Atom(B) denotes the set of atoms of B.

Let $\mathrm{k}$ be a non-zero natural number from $\mathrm{N}$. A k-partition of an element a from the Boolean algebra $B$ is a sequence $\{b(1), \ldots, b(k)\}$ of pairwise disjoint non-zero elements such as $a=b(1) U$ ...... $\mathrm{U} b(\mathrm{k})$. The formula $(\mathrm{b}(1), \ldots, \mathrm{b}(\mathrm{k}) \mid \mathrm{a})$ denotes that $\{\mathrm{b}(1), \ldots, \mathrm{b}(\mathrm{k})\}$ is a k-partition of $\mathrm{a}$.

Consider the new computable language $\mathrm{L}(0)=\mathrm{L}(\mathrm{BA}) \mathrm{U}\{\mathrm{P}(1, \mathrm{k}): \mathrm{k} \in \mathrm{N})\}$, where $\mathrm{P}(1, \mathrm{k})$ is a computable predicate.

b) Let $\mathrm{B}$ be a Boolean algebra. $\mathrm{An} \mathrm{L}(0)$ structure $\mathrm{B}(\mathrm{col})=(\mathrm{B},\{\mathrm{Pk}), \mathrm{k} \in \mathrm{N}\}$, is a coloured algebra, named "col", if there exists a computable sequence of $L(B A)$ formulas $\{$ phik $(x, y(k)), k \in N\}$, such that for any $\mathrm{k}$, there is a tuple $\mathrm{b}(\mathrm{k})$ from $\mathrm{B}$ with the isomorphism property:

$$
\mathrm{B}(\mathrm{col}):=\forall \mathrm{x}:(\operatorname{Pk}(\mathrm{x}) \square \operatorname{phik}(\mathrm{x}, \mathrm{b}(\mathrm{k}))
$$

Such a sequence $\{$ phik, $k \in N$ \}, is called a colouring sequence of $B$ (col). The Boolean algebra $B$ is called the underlying algebra of $\mathrm{B}(\mathrm{col})$.

Coloured algebras are introduced e.g. in (BazhenovN.A., 2014).The informal explanation of the term "coloured algebra" is as follows. We treat the predicates $\mathrm{Pk}$ as colours and assign these colours to elements of a Boolean algebra B. Note the important difference between this colouring and a graph colouring: we do not require an element of B to have only one colour. This last mathematical property is essential in handling biological excitations and flows.

Definition 5: A coloured algebra $\mathrm{B}(\mathrm{col})$ is atomic if its underlying algebra $\mathrm{B}$ is an atomic Boolean algebra.

Definition 6: A coloured algebra over a coloured operand $\mathrm{P}($.$) is then a map of operands \mathrm{A}: \mathrm{P}($. $\rightarrow$ EndU. One can also say that $\mathrm{A}$ is a representation of $\mathrm{P}$.

Definition 7: Let a set of functions $G$ act on two manifolds $M$ and N. A mapping f: $M \square N$ is equivariant if:

$$
\forall \mathrm{g} \in \mathrm{G}, \forall \mathrm{z} \in \mathrm{M}, \forall \mathrm{z} \in \mathrm{N}: \mathrm{f}^{*}(\mathrm{~g}(\mathrm{z}))=\mathrm{g} *(\mathrm{f}(\mathrm{z}))
$$

Finally, as references for standard terminology concerning operands, collections, ideals, presentations, Lie groups, etc. we recommend (May J.P. ,1972), (Ginzburg V.\& Kapranov M.M. ,1994)(Markl M.,1996)(Lada T. \& StasheffJ.D., 1993).

\subsection{Relevant Results for Bio-Inspired Quantum Computing Architectures}

Now that the stage has been set in the previous paragraphs, we highlight some key mathematical results on coloured algebras which are relevant for the proposed quantum computing architecture (Borza P.N. \& Pau L.-F., 2016). 
Theorem 1: Let us recall coloured operands describing diagrams of algebras.

a) Fix a (finite) set of colours $\mathbf{C}$ and consider an operand $P()=.\left\{P_{n}, n \geq 1\right\}$ such that each $P_{n}$ decomposes into the direct sum:

$$
\mathrm{P}_{\mathrm{n}}=\sum_{\mathrm{c}} \otimes \mathrm{P}_{\mathrm{c} ; \mathrm{c} 1, \ldots, \mathrm{cn}} \mathrm{c}, \mathrm{c} 1, \ldots, \mathrm{cn} \in \mathbf{C}
$$

where the summation runs over all colours $\mathrm{c} ; \mathrm{c} 1, \ldots, \mathrm{cn} \in \mathbf{C}$.

b) It is required that the decomposition (1) to be, in the obvious sense, $\Sigma_{\mathrm{n}}$-equivariant.

c) We also demand the following. Let $n \in \mathbf{N}$, and $x \in P_{c} ; c 1, \ldots, c n$ and $x_{i} \in P\left(d_{i} ; d(i, 1), \ldots, d(i\right.$, ki) ), $1 \leq \mathrm{i} \leq \mathrm{n}$. Then we require that the non-triviality of the decomposition $\mathrm{x}\left(\mathrm{x}_{1}, \ldots, \mathrm{x}_{\mathrm{n}}\right)$ implies that:

$$
\forall \mathrm{i}, 1 \leq \mathrm{i} \leq \mathrm{n}: \quad \mathrm{d}_{\mathrm{i}}=\mathrm{c}_{\mathrm{i}}(2)
$$

in which case it is proven in (MillerR., 2009) that:

$$
\mathrm{x}\left(\mathrm{x}_{1}, \ldots, \mathrm{x}_{\mathrm{n}}\right) \in \mathrm{P}_{\mathrm{c}} ; \mathrm{d}(1,1), \ldots, \mathrm{d}(1, \mathrm{k} 1), \ldots, \mathrm{d}(\mathrm{n}, 1), \ldots, \mathrm{d}(\mathrm{n}, \mathrm{kn})
$$

Interpretation: The intuitive meaning of (2) is that one may plug the element $\mathrm{x}_{\mathrm{i}}$ into the $\mathrm{i}$-th slot of the element $x$, if and only if the colour of the output of $x_{i}$ is the same as the colour of the $i$-th input of $\mathrm{x}$, ; otherwise the composition is defined to be zero. This is essential to achieve disambiguation in quantum computing.

Theorem 2:Nielsen M.A. \& Chuang I.L. (2010) showed that a computable atomic Boolean algebra $\mathrm{B}$ is decidable iff. the set of atoms Atom(B) is computable.

Interpretation: To achieve decidability in quantum computing, it is enough to characterize the set of atoms of the algebra representing the pathways of a functional block. This also means that if this functional block can be represented by a computable atomic Boolean algebra, itis not necessary always to exploit all qubit values.

Theorem 3: Bazhenov N. (2015) proves the following corollary. Suppose that $B(\mathrm{col})=\left(\mathrm{B}, \mathrm{P}_{\mathrm{k}}\right), \mathrm{k}$ $\epsilon \mathbf{N}$, is a computable atomic coloured algebra, and $\left\{\mathrm{phi}_{\mathrm{k}}\left(\mathrm{x}, \mathrm{y}_{\mathrm{k}}\right)\right\}, \mathrm{k} \in \mathbf{N}$, is a colouring sequence of $\mathrm{B}(\mathrm{col})$. The structure $\mathrm{B}(\mathrm{col})$ is decidable if and only if it satisfies the following conditions:

(i) The set of atoms Atom(B) is computable; and:

(ii) There exists a computable function $\mathrm{g}(\mathrm{x})$ such that for any $\mathrm{k}$, the value $\mathrm{g}(\mathrm{k})$ is equal to the Gödel number of some tuple $b_{k}(G o ̈ d e l$ numbering of a sequence,2018) with the property:

$\mathrm{B}(\mathrm{col}) \mathrm{I}=\forall \mathrm{x} \quad\left(\mathrm{P}_{\mathrm{k}}(\mathrm{x}) \rightarrow \operatorname{phi}_{\mathrm{k}}\left(\mathrm{x}, \mathrm{b}_{\mathrm{k}}\right)\right)$

and $b_{k}$ is the colouring sequence.

Interpretation: To achieve decidability in quantum computing, for functional blocks which can be imaged by a computable coloured algebra, such a computable function $\mathrm{g}(\mathrm{x})$ can serve as a test. 


\section{Supporting Biological Measurements}

\subsection{Scope}

The main idea is to discriminate between the intensity of excitation signals and their information content, by measuring changes in the nervous synapse biochemical load. This knowledge is essential to split the roles of the quantum excitation signals and the functional block responses, e.g. those in a synapse functional block in the proposed architecture.

More precisely: what represents the main reactivity in nerves: signal energy or the information flow carried by the nerves?

The measurements were done (Restian A., Borza P. N., Daghie Mircea V.,\& Nicolau N., 1985) by a combination of information excitations onto living bodies, and by titration of $17^{\text {th }}$ ketosteroids, which represent a global indicator of neural activity in synapsis chemical reactants (acetylcholine, adrenaline \& noradrenaline).They have found new relevance for the modelling in bio-inspired quantum processing of the basic functional block representing a synapse.

\subsection{Experimental Set-Up}

Were used several hundred laboratory male mice and rats, divided in groups of 12, grown in similar conditions and receiving for over one month the same nutrition before the experiments. For each experiment, two groups were used: one exposed to excitations, and the other not.

The first subgroup of mice was exposed for 16 hours to $30-80 \mathrm{~dB}$ acoustic information and $0,5-5$ lux (lumen.m ${ }^{-2}$ )white video signals generated by incandescent bulbs having a continuous spectrum in the visible domain(Calculating the Emission Spectra from Common Light Sources, accessed on $12 / 12$ / 2018), with 4-500 bits/minute information via audio/video signal modulation (state T1, or state T2). The acoustic signals were binary while the video signals were intensity modulated. The second sub group of mice were exposed to no information excitation (state T0). Both subgroups were fed in the same way.

The signal generator generates random excitations signals with binary intensities on an audio signal, resp. random on a video signal. These random changes are considered as effectively real changes of the information content transmitted to the living entities during the experiments(von Bertalanffy L., 1942).

Each excited subgroup was excited for 16 hours, and then put to rest until a new experiment, those being repeated every 24 hours. Every 24 hours, from all the mice's urine, adrenaline and noradrenaline were measured, as well as the assimilation of $17^{\text {th }}$ ketosteroids. The $17^{\text {th }}$ ketosteroids are the metabolic results of synapse reactions reflected in concentration of 17th ketosteroids in blood and urine of lab rats. Were also measured the adrenaline and nor-adrenaline values for lab rats.

The neural synapse metabolism was achieved via the titration of $17^{\text {th }}$ Ketosteroids in sacrificed mice to determine:

a) Catecholamines reflecting short time reactivity or organisms;

b) Liberated Hypophysis suprarenal steroids reflecting adaptation of organism. 
In some experiments, two drugs were administered to the target mice to observe their influence on the measurements; these two drugs were Diazepan \& Apivita (a natural product obtained from honey rich in fotihormons, sterols and free amino acids).

\subsection{Results of the Experiments}

Different experiments A-D were carried out with varying sound, light and information flow values. Tables 1-A/D provide the parameters of the experiments and the results. Experiments A and $\mathrm{B}$ were with different information data rates. Experiments $\mathrm{C}$ and $\mathrm{D}$ were with drug injections. In all Tables, the reported values are the shifts versus the rest stage of the mice subgroups not exposed to the experiments; values are given in micrograms or milligrams, and as \%.

\subsection{Interpretation of Results and Remarks}

The results demonstrate the first importance played by information versus energy of excitation signals in reactivity of living entities, as conjectured by von Bertalanffy L. (1942). This is a fundamental aspect referring the "sensitivity" of living entities which are more sensitive to the "content" of a signal versus its energy. The experiments focused on the effect of bits of information, by having selected a pseudo-random video \& audio signal generation signals before any adaption of the mice to the excitation signals.

A second aspect demonstrated by experiments illustrate the capability of the used methodology to put in evidence the influence of several therapeutic drugs on living entities, respectively the protective role played by these drugs against excessive informational flows. Thus, the methodology demonstrates a certain capability to be used in simple investigations related living entities adaptation and reactions at signals received. This is very interesting for the realization of the bio-inspired quantum processing functional blocks, taking technological excitation uncertainties into account with the resulting required adaptation.

An important remark is related to the quantitative interpretation of the informational content of signals. Thus, thinking at the information flow, the randomization of signals generated as excitations for living entities, respect only relatively the "random" characteristics. We can't have the $100 \%$ capability to determine how the living entities "interpret" the performed experiments. Also, this reactivity will be specific for other species of living entities and the methodology demonstrates a limited direct applicability. Even so, the first and second conclusions above still hold with a high degree of confidence.

\section{TABLE 1-A: Experiment A}

T0 (rest stage of subjects): $0 \mathrm{Lx}$ (lighting flow in lumen/m2): $36 \mathrm{~dB}$ (audio intensity in logarithmic scale measured near mice cages).

T1: Information data rate: 231 bit/min: 0,5 Lx (lighting flow in lumen/m2): $54 \mathrm{~dB}$ (audio intensity in logarithmic scale measured near mice cages).

T2: Information data rate: $231 \mathrm{bit} / \mathrm{min} ; 3 \mathrm{Lx}$ (lighting flow in lumen/m2): $68 \mathrm{~dB}$ (audio intensity in logarithmic scale measured near mice cages). 
International Journal of Computer Science \& Information Technology (IJCSIT) Vol 11, No 4, August 2019

\begin{tabular}{|c|c|c|c|c|c|c|}
\hline Step & $\begin{array}{l}\text { Adrenaline+ } \\
\text { noradrenalin }\end{array}$ & $\begin{array}{l}\text { Adrenaline+ } \\
\text { noradrenalin }\end{array}$ & $\begin{array}{l}\text { Adrenaline+ } \\
\text { noradrenalin }\end{array}$ & $\begin{array}{l}17 \\
\text { ketosteroids }\end{array}$ & $\begin{array}{l}17 \\
\text { ketosteroids }\end{array}$ & $\begin{array}{l}17 \\
\text { ketosteroids }\end{array}$ \\
\hline & $\begin{array}{l}\text { Micrograms/24 } \\
\mathrm{h} \quad+/- \\
=\text { Standard } \\
\text { deviation }\end{array}$ & $\begin{array}{l}\text { Growth of } \\
\text { measured } \\
\text { values }\end{array}$ & $\begin{array}{l}\text { Growth of } \\
\text { measured } \\
\text { values }\end{array}$ & $\begin{array}{l}\text { Micrograms } \\
/ 24 \mathrm{~h}+/-= \\
\text { Standard } \\
\text { deviation }\end{array}$ & $\begin{array}{l}\text { Growth of } \\
\text { measured } \\
\text { values }\end{array}$ & $\begin{array}{l}\text { Growth of } \\
\text { measured } \\
\text { values }\end{array}$ \\
\hline & & Shift \% & $\mathrm{T} 1$ & & Shift \% & $\mathrm{T} 1$ \\
\hline T0 & $10,5+/-6,3$ & - & - & $0,93+/-0,13$ & - & - \\
\hline $\mathrm{T} 1$ & $83,1+/-29,7$ & +691 & - & $\begin{array}{l}1,34+/- \\
0,10\end{array}$ & +44 & - \\
\hline $\mathrm{T} 2$ & $90,0+/-13,2$ & +758 & +8 & $\begin{array}{ll}1,42 & +/- \\
0,09 & \end{array}$ & +53 & +6 \\
\hline
\end{tabular}

\section{TABLE 1-B : Experiment B}

T0 (rest stage of subjects): $0 \quad \mathrm{Lx}$ (lighting flow in lumen/m2); $36 \mathrm{~dB}$ (audio intensity in logarithmic scale measured near mice cages).

T1- Information data rate: 4 bits/min; $3 \mathrm{Lx}$ (lighting flow in lumen/m2); $68 \mathrm{~dB}$ (audio intensity in logarithmic scale measured near mice cages).

T2- Information data rate: 4 bits/min; 0,5 Lx(lighting flow in lumen/m2); $54 \mathrm{~dB}$ (audio intensity in logarithmic scale measured near mice cages).

\begin{tabular}{|c|c|c|c|c|c|c|}
\hline Step & $\begin{array}{l}\text { Adrenaline+ } \\
\text { noradrenalin }\end{array}$ & $\begin{array}{l}\text { Adrenaline+ } \\
\text { noradrenalin }\end{array}$ & $\begin{array}{l}\text { Adrenaline+ } \\
\text { noradrenali } \\
n\end{array}$ & $\begin{array}{l}17 \\
\text { ketosteroids }\end{array}$ & $\begin{array}{l}17 \\
\text { ketosteroids }\end{array}$ & $\begin{array}{l}17 \\
\text { ketosteroids }\end{array}$ \\
\hline & $\begin{array}{l}\text { Micrograms/ } \\
24 \mathrm{~h} \mathrm{+}+/- \\
=\text { Standard } \\
\text { deviation }\end{array}$ & $\begin{array}{l}\text { Growth of } \\
\text { measured } \\
\text { values }\end{array}$ & $\begin{array}{l}\text { Growth of } \\
\text { measured } \\
\text { values }\end{array}$ & $\begin{array}{l}\text { Micrograms } \\
/ 24 \mathrm{~h}+/-= \\
\text { Standard } \\
\text { deviation }\end{array}$ & $\begin{array}{l}\text { Growth of } \\
\text { measured } \\
\text { values }\end{array}$ & $\begin{array}{l}\text { Growth of } \\
\text { measured } \\
\text { values }\end{array}$ \\
\hline & & Shift $\%$ & $\mathrm{~T} 1$ & & Shift & T1 \\
\hline T0 & $2,42+/-0,76$ & - & - & $\begin{array}{ll}0,33 & +/- \\
0,02 & \end{array}$ & - & - \\
\hline $\mathrm{T} 1$ & $2,72+/-0,64$ & +12 & - & $\begin{array}{l}0,52 \\
0,09\end{array}$ & +58 & - \\
\hline $\mathrm{T} 2$ & $5,48+/-1,21$ & +124 & +100 & $\begin{array}{l}1,08 \\
0,11\end{array}$ & +227 & +108 \\
\hline
\end{tabular}

TABLE 1-C: Experiment C:Wasinjected 2 times/24 hours: Diazepam $0.571 \mathrm{mg} / \mathrm{Kg}$ body

T0 (rest stage of subjects): $0 \quad \mathrm{Lx}$ (lighting flow in lumen/m2); $36 \mathrm{~dB}$ (audio intensity in logarithmic scale measured nearmice cages).

T1-Information data rate: 231 bits/min; $3 \mathrm{Lx}$ (lighting flow in lumen/m2) $68 \mathrm{~dB}$ (audio intensity in logarithmic scale measured near mice cages). 
International Journal of Computer Science \& Information Technology (IJCSIT) Vol 11, No 4, August 2019

\begin{tabular}{|l|l|l|l|l|}
\hline Step & $\begin{array}{l}\text { Adrenaline+ } \\
\text { noradrenalin }\end{array}$ & $\begin{array}{l}\text { Adrenaline+ } \\
\text { noradrenalin }\end{array}$ & 17 ketosteroids & $\begin{array}{l}17 \\
\text { ketosteroids }\end{array}$ \\
\hline & $\begin{array}{l}\text { Micrograms/24 } \\
\text { h }+/- \\
\text { =Standard } \\
\text { deviation }\end{array}$ & $\begin{array}{l}\text { Growth of } \\
\text { measured } \\
\text { values }\end{array}$ & $\begin{array}{l}\text { Micrograms/24 } \\
\text { h } \\
\text { =Standard } \\
\text { deviation }\end{array}$ & Crestera \\
\hline & & Shift $\%$ & & Shift \% \\
\hline & & & & \\
\hline T0 & $10,49+/-2,50$ & - & $1,17+/-0,09$ & - \\
\hline T1 & $7,58+/-1,85$ & +28 & $0,62+/-0,11$ & +47 \\
\hline
\end{tabular}

TABLE 1-D: Experiment D:Were injected 0,35 g/kg Apivitasdrug, rich in phytohormones sterolis and free amino acids; the drug increases the differences between ATP/ADP/AMP in favour of ATP

T0 (rest stage of subjects): $0 \quad \mathrm{Lx}$ (lighting flow in lumen $/ \mathrm{m} 2$ ); $36 \mathrm{dBdB}$ (audio intensity in logarithmic scale measured near mice cages).

T1- Information data rate: $231 \mathrm{bits} / \mathrm{min} ; 3 \mathrm{Lx}$ (lighting flow in lumen/m2); $68 \mathrm{dBdB}$ (audio intensity in logarithmic scale measured near mice cages).

\begin{tabular}{|l|l|l|l|l|}
\hline Step & Adrenaline+ & Adrenaline+ & $\begin{array}{l}17 \\
\text { ketosteroids }\end{array}$ & $\begin{array}{l}17 \\
\text { ketosteroids }\end{array}$ \\
\hline & $\begin{array}{l}\text { Milligrams/24 } \\
\text { h +/- } \\
=\text { Standard } \\
\text { deviation }\end{array}$ & $\begin{array}{l}\text { Growth of } \\
\text { measured } \\
\text { values }\end{array}$ & $\begin{array}{l}\text { Milligrams/24 } \\
\text { h } \\
\text { =Standard } \\
\text { deviation }\end{array}$ & $\begin{array}{l}\text { Growth of } \\
\text { measured } \\
\text { values }\end{array}$ \\
\hline & & Shift \% & & Shift \% \\
\hline & & & & \\
\hline T0 & $5,76+/-1,19$ & - & $1,13+/-0,11$ & - \\
\hline T1 & $8,06+/-2,22$ & +40 & $0,92+/-0,19$ & +19 \\
\hline
\end{tabular}

\section{Implications For The Proposed Quantum Computing ARCHitecture}

This Section addresses the consequences of the mathematical analysis and the biological experiments described above, for the bio-inspired quantum computing architecture in (Borza P.N. \& Pau L.-F., 2016).

\subsection{Impact on Decoherence}

Decoherence in quantum computing is formulated within the Semigroup approach in (Lidar D.A., Chuang I.L. \& Whaley K.B.,1998), (Ritter G., 2005). Error generators are identified to the generators of a Lie algebra. In this way one may produce a comprehensive description which includes as a special case the often-assumed spin-boson model. A generic condition is presented for error-less quantum computation; it is required that decoherence-free subspaces are spanned by 
those states which are annihilated by all the generators. It is first shown that these subspaces are stable to perturbations, and next that universal quantum computation is possible within them.

Decoherence remains the main obstacle to the speedup promised by quantum computers by some algorithms such as (ShorP.W., 1994), (GroverL.K., 1997),(ShorP.W., 1995). To this end, a remarkable theory of quantum error correction codes (QECC) has been designed (Calderbank A.R.\& Shor P.W. ,1996)(Ginzburg V.\& Kapranov M.M. ,1994) (Duan L.-M. \& Guo G.-C. ,1998); it relies on encoding a logical quantum bit (qubit) in the larger Hilbert space of several physical qubits. Thiserror-correction approach assumesthat the most probable errors are those which occur independently to a few qubits during a reasonable time interval.

The existence of decoherence-free (DF) subspaces has been shown by projecting multiple copies of a quantum computer onto symmetric subspaces(Barenco A., Berthiaume A., Deutsch D., Ekert A., Jozsa R. \& Macchiavello C. ,1997), (WangZ. ,2008), and by use of a group theoretic argument(HayashiM., 2017).The construction of these subspaces was performed explicitly for certain collective error processes in the spin-boson model (Palma G.M., Suominen K.-A.\& Ekert A.K. ,1996)(Zanardi P. \&Rasetti M. ,1997).

By directly linking the coloured algebras introduced in this paper, to resolve decoherence by the bio-derived colours in quantum excitation signals, a real gain can be achieved at realization stage.

\subsection{Impact of Synapse Binary Excitation}

Obviously sound and video excitations of rat's synapse do not mimic perfectly the quantum interactions taking place inside the architecture proposed by Borza P.N. \& Pau L.-F. (2016), if it were to be excited by sound and video in a similar way. Linking up with the section on coloured algebras, binary sounds would be modelled by a first simple algebra, while coloured video would be modelled by a second algebra (with light colour modulation). There are some lessons learnt however:

-biological saturation effects occur, but, due to feedback effects, it is not proportional to bit rates (Tables 1-A, Tables 1-B);

-the signal type (binary sound, or long signals like an analogue video) has a significant effect, in that video provides the highest levels of excitation, with or without adrenaline (Tables 1-A to -C); this may lead to the assumption that long qubits allow for the most extensive processing in quantum architectures mimicking synapses;

-Growing of measured values of 17 ketosteroid responses are significantly affected by the mix between the binary audio and the modulated video (Table 1-B), with this observation required more experimental research. This could correspond to the integral measure of excitation information. This opens the conjecture that the video modulation enables higher sensitivity, meaning that modelling quantum architectures using coloured algebras may allow to exploit wider sensitivity margins. This is very important in engineering terms, by reducing required energy or reducing cooling requirements.

\section{CONCLUSION AND OPEN RESEARCH ISSUES}

As stated above, this article reports on progress in a fundamental and experimental research on the architecture of quantum computers based on biological processes and new results in particle 
physics (Borza, P.N. \& Pau, L.-F. ,2016). It has been shown that by directly linking the coloured algebras to resolve decoherence to the bio-derived colours in quantum excitation signals, a real gain can be achieved at realization stage. Is also shown experimentally that one can distinguish amid the strength of excitation signals and the information content, by measuring changes in the nervous synapse biochemical load. This information is vital to split the roles of the quantum excitation signs and the useful block responses, e.g. those in a synapse functional block in the planned architecture.

While the research presented in this paper addresses two specific aspects of the proposed architecture, it also allows to prioritize further research steps towards the architectural specification and realization. They represent short term open issues:

1) The biological processes often have been studied elsewhere and for some of them reference control models exist, which can be calibrated with the data of Tables 1-A/D. Once this is done, and control models may eventually be refined, the simulation of the corresponding functional realizations car be initiated. With these functional realizations, flows of particles and their propagation paths can be estimated for later realization with quantum processing elements. To all such quantum processing elements and flows, the needed colouring schemes can be designed, which in turn help addressing decoherence inside each such quantum processing elements.

2) After the above steps, should be addressed the design of a compiler able to convert a suitable language into the execution in quantum computing on the basic quantum processing elements and the quantum functional realizations described in the previous subparagraph. The scientific challenge is here to cater for the state super positions with very large simultaneous parallelization and execution. The first study would use only very few input-output related quantum processing elements and external interfaces, and very few biological inspired quantum functional realizations.

3) Prototyping would follow the approach described in (Kleinert M., Conradi H., Schrenk B. \&Hübel H. ,2019), blending on-chip ultrathin film elements, nonlinear crystals for excitation signals, and single photon detectors.

\section{REFERENCES}

[1] ABACUS European Union FP7-ICT Project (2016). Parallel computing based on designed networks explored by self-propelled biological agents, Coordinated by Lund University, Sweden. http://abacus4eu.com and www.cordis.europa.eu/news/rcn/124861

[2] Barenco, A., Berthiaume, A., Deutsch, D., Ekert, A., Jozsa, R. \& Macchiavello, C. (1997).Quantum Kolmogorov complexity, SIAM Journal on Computers, 26, 1541-1555. www.sciencedirect.com/science/article/pii/S0022000001917659

[3] Bazhenov, N.A. (2014). Autostability spectra for Boolean algebras, Algebra logic, 53, 502-505.

[4] Bazhenov, N.A. (2015). Prime model with no degree of autostability relative to strong constructivizations, in: Beckman, A., Mitrana, V.,\&Soskova, M. (Eds), Evolving computability: Proc. 11 th Conference on computability in Europe, CIE, Bucharest, June 29-July 3, 117-126. Published as: Lecture Notes in Computer science, Theoretical computer science and general issues, Vol. 9136, Springer Germany. ISBN: 978-3-319-20028-6 
International Journal of Computer Science \& Information Technology (IJCSIT) Vol 11, No 4, August 2019

[5] Beckmann, A., Mitrana, V. \& Soskova, M. (Eds) (2015). Evolving Computability: 11th Conference on Computability in Europe, CiE, Bucharest, Romania, June 29-July 3, 2015. Published as: Lecture Notes in Computer science, Theoretical computer science and general issues, Vol. 9136, Springer, Germany. ISBN: 978-3-319-20028-6

[6] Bertalanffy (von), L. (1942).Handbuch der Biologie, Akademische Verlagsgesellschaft Athenaion, Konstanz. www.lccn.loc.gov/65031183

[7] Borza, P.N. \& Pau, L.-F. (2016).From digital computers to quantum computers based on biological paradigms and progress in particle physics, International Journal of advanced computer technology (IJACT), 5(1), 28-37. ISSN:2319-7900. http://www.ijact.org/volume5issue1.htm, \&http://arxiv.org/abs/1609.07642

[8] Calculating the Emission Spectra from Common Light Sources, accessed on 12 /12 / 2018 at address : https://www.comsol.com/blogs/calculating-the-emission-spectra-from-common-light-sources/ or: https://www.suprabeam.com/uk/light

[9] Calderbank A.R.and Shor P.W. (1996).Entanglement-assisted quantum error-correcting codes, Physics Review, A-54, 1098-1121. www.link.aps.org/doi/10.1103/PhysRevA.54.1098

[10] Cenzer,D. (2000).Pi (0,1) classes in computability theory, in: Griffor,E.R. (Ed), Handbook of computability theory, Studies in Logic Foundations of Mathematics, 140, 37-85. Elsevier Science BV, Amsterdam.

[11] Chevalley, C. (1956).Fundamental concepts of algebra, Academic Press, New York.

[12] Chang, C.C.,\& Keisler, H.J. (1973). Model theory, North Holland, Amsterdam.

[13] Duan, L.-M. \& Guo, G.-C. (1998). Quantum error correction for beginners, Physics Review, A-57, 737-752. www.iopscience.iop.org/article/10.1088/0034-4885/76/7/076001/meta

[14] Gershenfeld, N. \& Chuang, I.L. (1997).Bulk spin-resonance quantum computation, Science, 275, 350-382. www.science.sciencemag.org/content/275/5298/350

[15] Ginzburg, V. \& Kapranov, M.M. (1994). Koszul duality for operands,Duke Mathematics Journal, 76(1), 203-272.

[16] Gödel numbering of a sequence (2018).

https://en.wikipedia.org/wiki/G\%C3\%B6del_numbering_for_sequences

[17] Grandis, M. (1999). On the homotropy structure of strongly homotopy associative algebras, Journalof Pure and Applied Algebra, 134(1), 15-81.

[18] Grover, L.K. (1997).Implementation of a three-quantum-bit search algorithm, Physics Review Letters, 79, 4709-4723. www.aip.scitation.org/doi/abs/10.1063/1.125846

[19] Hayashi, M. (2017). Group representation for quantum theory, Springer Verlag, Berlin. ISBN 978-3$319-44906-7$

[20] Jockusch, C.G. \& Soare, R.I. (1972).Pi(0,1) classes and degrees of theories, Transactions American Mathematical Society, 173,33-56. 
International Journal of Computer Science \& Information Technology (IJCSIT) Vol 11, No 4, August 2019

[21] Kleinert, M.,Conradi,H., Schrenk, B. \& Hübel H. (2019), UNIQORN: making quantum photonics affordable, Laser Focus World, April 2019, 27-31.

[22] Lada, T. \& Stasheff, J.D. (1993). Introduction to the Lie algebras for physicists, International Journal of Theoretical Physics, 32(7), 1087-1103.

[23] Lidar,D.A., Chuang, I.L. \&Whaley, K.B. (1998). Decoherence Free Subspaces for Quantum Computation. https://arxiv.org/pdf/quant-ph/9807004.pdf

[24] Lucks, J.B. \&Arkin, A.P. (2011). The hunt for the biological transistor, IEEE Spectrum, 48(3), 3439.

[25] Markl, M. (1992). A cohomology theory for A(m)-algebras and applications, Journal of Pure and Applied Algebra,83, 141-175.

[26] Markl, M. (1996). Models for operands, Communications in Algebra, 24(4),1471-1500.

[27] Markl, M. (1999). Homotopy algebras are homotopy algebras. https://arxiv.org/abs/math/9907138

[28] Markl, M. (2000). Ideal perturbation lemma, Communications in Algebra,29(11).doi: 10.1081/AGB100106814

[29] Markl,M. (2018). Homotopy diagrams of algebras.https://arxiv.org/pdf/math/0103052.pdf

[30] May, J.P. (1972).The Geometry of Iterated Loop Spaces, Lecture Notes in Mathematics.SpringerVerlag, Berlin.doi:10.1007/BFb0067491. ISBN: 978-3-540-05904-2.

[31] Mermin, N.D. (2007). Quantum computer science: an introduction, Cambridge University Press, Cambridge UK.

[32] Miller,R. (2009).d-computable categoricity for algebraic fields, Journal of SymbolicLogic, 74,13251351

[33] Nielsen, M.A. \&Chuang, I.L. (2010). Quantum computation and quantum information, Cambridge University Press, Cambridge UK.

[34] Palma, G.M., Suominen, K.-A.\&Ekert,A.K. (1996).Quantum computation and dissipation, Proceedings Royal Society London, A 452, 567-584.

[35] Restian, A., Borza, P. N., Daghie Mircea, V.\&Nicolau,N. (1985). Metoda si aparat de investigare a influentei solicitarilor informationale esupra organismului (Method and apparatus for investigating the influence of information on living organisms), Romanian Patent Invention claim no 119168 of 17 June 1985, assigned to Institutul de igiena si sanatate publica, Bucarest. Patent grantedasRomanian Patent no 93122 of 24 June 1987.

[36] Ritter, G. (2005). Lie Algebras and Suppression of Decoherence in Open Quantum Systems, Physical Review, A-72(1).

www.researchgate.net/publication/2196159_Lie_Algebras_and_Suppression_of_Decoherence_in_O pen_Quantum_Systems

[37] Schäfer, V.M. et al (2018). Fast quantum logic gates with trapped-ion qubits, Nature, 555, 7578.doi: 10.1038 /nature 25737 
International Journal of Computer Science \& Information Technology (IJCSIT) Vol 11, No 4, August 2019

[38] Shor, P.W. (1994). Polynomial-time algorithms for prime factorization, in:Proceedings of the 35th Annual Symposium on the Foundations of Computer Science, Goldwasser, S. (Ed), IEEE Computer Society Press, Los Alamitos, CA, 124-142.www.arxiv.org/abs/quant-ph/9508027

[39] Shor, P.W. (1995). Scheme for reducing decoherence in quantum memory, Physics Review, A-52, 2493-2496. www.researchgate.net/publication/13375764_Shor_P_W_Scheme_for_reducing

[40] Vuillemin, J. (1974). Correct and optimal implementation of recursion in a simple programming language, Journal of Computer Systems Science, 9, 332-351.

[41] Wang,Z. (2008). Topological quantum computation, Conference board of the mathematical sciences (CBMS),American Mathematical society Regional conference series in mathematics No 112, Providence RI. www.ams.org/bookpages/cbms=112

[42] Watson,T.F. et al (2018). A programmable two-qubit quantum processor in silicon, Nature,555, 633-637. doi: 10.1038/nature25766

[43] Zanardi, P. \&Rasetti,M. (1997). Noiseless quantum codes, Physics Review Letters, 79(17), 3306 3325.

[44] Zanardi, P.\&Rasetti,M. (1999). Non-adiabatic holonomic quantum computation, Modern Physics Letters, B-11, 1085-1101. 